\title{
DIFERENCIAS EN UN CULTIVO DE TOMATE REGADO CON AGUA DE MAR DESALINIZADA Y MEZCLADA CON AGUA DE POZO, CULTIVADO EN SUELO Y EN HIDROPÓNICO.
}

Marín Membrive, $P .{ }^{1}$ Valera Martínez, D. L. ${ }^{1}$ Reca Cardeña, J. ${ }^{1}$ Maestre Valero, J. ${ }^{2}$ Moreno Teruel, M.A. ${ }^{1}$ y Urrestarazu Gavilán, $M{ }^{1}$

${ }^{1}$ CIAIMBITAL, Universidad de Almería. patriciamarin@ual.es

${ }^{2}$ ETSIA, Universidad Politécnica de Cartagena, España. josef.maestre@upct.es

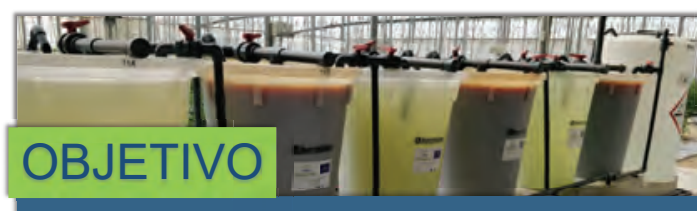

Diferencias en la producción, consumo de agua y aporte de fertilizantes

derivadas del uso de agua de mar desalinizada (T1) y agua de la mezcla de ésta con agua de pozo (T2 yT3)

en dos ciclos cortos de un cultivo de tomate bajo invernadero

cultivado en suelo (S) y en hidropónico (H) con reutilización de drenajes.

\section{RESULTADOS}

$$
\text { Ciclo otoño-invierno }
$$

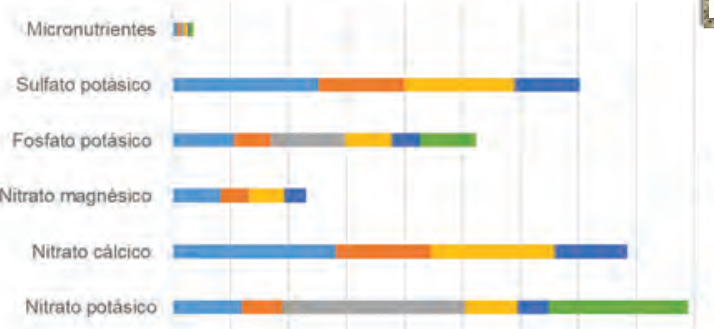

Nitrato amónico en:

$\begin{array}{llllllllll}0 & 20 & 40 & 60 & 80 & 100 & 120 & 140 & 160 & 180\end{array}$ Ciclo primavera-verano

Micronutrientes

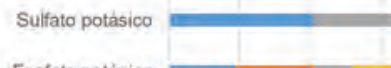

Fosfato potásico
Nitrato magnésico

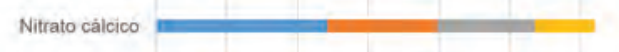

Nitrato potàsico
Nitrato amónico

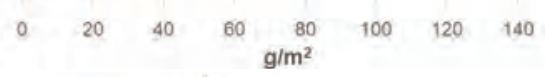

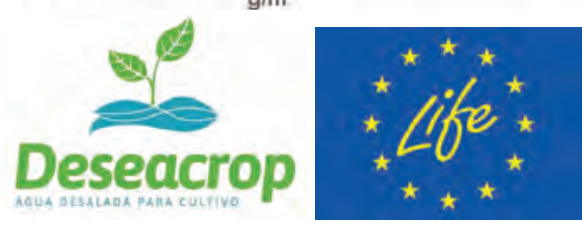

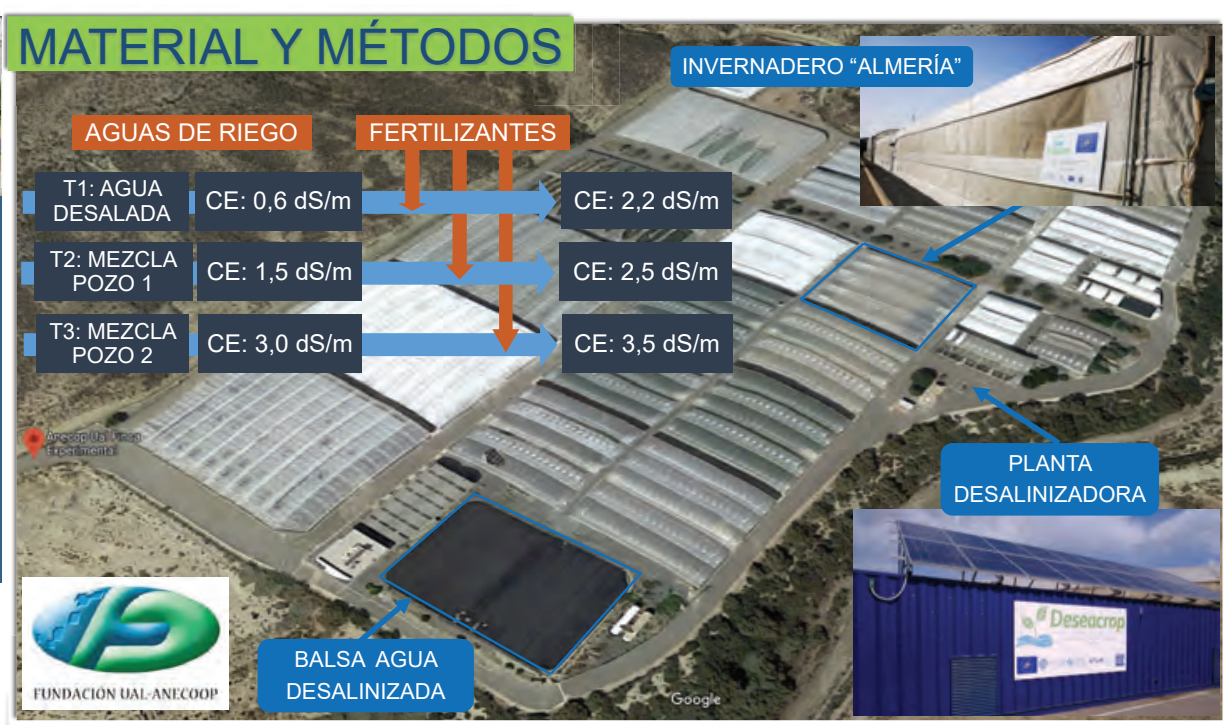

\begin{tabular}{|c|c|c|c|c|c|c|}
\hline \multirow{2}{*}{\multicolumn{2}{|c|}{$\begin{array}{c}\text { APORTES } \\
\text { FERTILIZANTES }\end{array}$}} & \multicolumn{5}{|c|}{ PRODUCCIÓN (P) Y CONSUMO DE AGUA (A) } \\
\hline & & \multirow{2}{*}{\multicolumn{3}{|c|}{$\begin{array}{c}\text { Ciclo de Otoño-Invierno } \\
(10 / 09 / 19-15 / 02 / 20)\end{array}$}} & \multirow{2}{*}{\multicolumn{2}{|c|}{$\begin{array}{c}\text { Ciclo de Primavera-Verano } \\
(18 / 03 / 19-02 / 07 / 19)\end{array}$}} \\
\hline \multirow{8}{*}{$\begin{array}{l}=\mathrm{T} 1-\mathrm{H} \\
=\mathrm{T} 2-\mathrm{H} \\
=\mathrm{T} 3-\mathrm{H} \\
=\mathrm{T} 1-\mathrm{S} \\
=\mathrm{T} 2-\mathrm{S} \\
=\mathrm{T} 3-\mathrm{S}\end{array}$} & & & & & & \\
\hline & & & $P\left(\mathrm{~kg} / \mathrm{m}^{2}\right)$ & $A\left(\mathrm{~kg} / \mathrm{m}^{3}\right)$ & $P\left(\mathrm{~kg} / \mathrm{m}^{2}\right)$ & $A\left(\mathrm{~kg} / \mathrm{m}^{3}\right)$ \\
\hline & & T1-H & 5,32 & 22,61 & 8,01 & 22,43 \\
\hline & & T2-H & 4,57 & 19,42 & 7,84 & 21,23 \\
\hline & & T3-H & 4,42 & 18,79 & $=$ & - \\
\hline & & T1-S & 4,59 & 25,73 & 6,18 & 30,34 \\
\hline & & T2-S & 4,56 & 25,56 & 6,26 & 31,27 \\
\hline & & T3-S & 4,63 & 25,95 & - & - \\
\hline
\end{tabular}

\section{CONCLUSIONES}

Según la técnica de cultivo empleada, el cultivo en hidropónico ha obtenido las mayores producciones, aunque ha sido menos eficiente en el uso de agua y se han aportado más fertilizantes.

El tratamiento regado con agua desalada en hidropónico, ha tenido las mayores producciones, ha sido más eficiente en el uso de agua y se han aportado más fertilizantes en el ciclo de otoño-invierno.

En el suelo, la mayor producción y eficiencia de agua ha correspondido al tratamiento con el agua de riego de mayor salinidad en cada ciclo, con un menor aporte de fertilizantes.

Proyecto financiado por el programa LIFE+ de la Unión Europea (LIFE16-ENV-ES-000341)

http://www.deseacrop.eu/

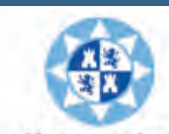

Universidad

Politécnica de Cartagena

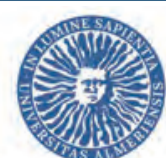

UNIVERSIDAD 